Results: One hundred and seventy-four patients were included, 142 (81.6\%) patients from the outpatient clinic and $32(18.4 \%)$ patients hospitalized. The mean age was $45.1\left(\mathrm{SD}_{ \pm 15.8}\right)$ years, $135(77.6 \%)$ were females, $54(31 \%)$ patients were under initial diagnosis evaluation, 30 (17.2\%) had RA, 25 (14.4\%) patients had SLE, $15(8.6 \%)$ patients had psoriatic arthritis, $12(6.9 \%)$ patients had systemic sclerosis, $6(3.4 \%)$ patients had dermatomyositis. The main reasons for consultation in hospitalized patients were acute lupus (15.6\%), subacute lupus $(12.5 \%)$, purpura $(12.5 \%)$, cutaneous vasculitis $(9.4 \%)$, urticarial dermatitis $(9.4 \%)$, dermatomyositis $(6.3 \%)$ and others $(34.3 \%)$. The consultation requested was: $156(89.7 \%)$ to Dermatology and $18(10.3 \%)$ to Rheumatology. The type of treatment prescribed was topic/local in $37(21.3 \%)$ patients, systemic in 25 $(14.4 \%)$ and both in $92(52.9 \%)$ patients. The final diagnoses were related to the underlying disease in $102(77 \%)$ patients and unrelated in $40(23 \%)$ patients. The agreement between initial clinical suspicion and final diagnoses reached $75.9 \%$ between Rheumatology and Dermatology services. Figure 1.

Conclusion: The collaboration between Rheumatology and Dermatology services are very important. Most of the patients were under initial evaluation. All the rheumatologists and dermatologists should be aware of the interdependence from both specialties to give the best quality of care to the patients.

REFERENCES:

[1] Samycia M, McCourt C, Shojania K, Au S. Experiences From a Combined Dermatology and Rheumatology Clinic: A Retrospective Review. J Cutan Med Surg. 2016;20(5):486-489. doi:10.1177/1203475416649138.

[2] Theodorakopoulou E, Dalamaga M, Katsimbri P, Boumpas DT, Papadavid E. How does the joint dermatology-rheumatology clinic benefit both patients and dermatologists?. Dermatol Ther. 2020;33(3):e13283. doi:10.1111/ dth. 13283

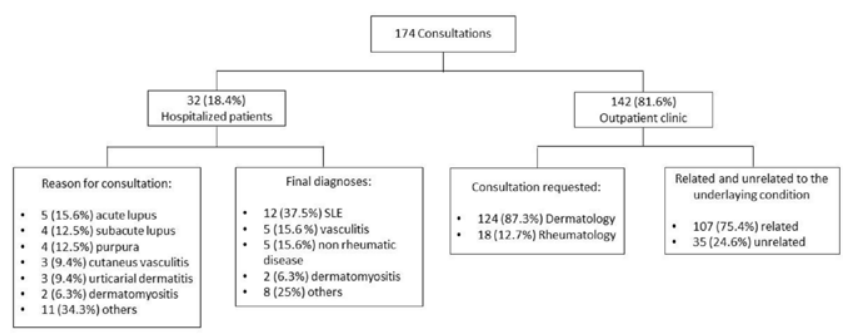

Figure 1.

Disclosure of Interests: None declared

DOI: 10.1136/annrheumdis-2021-eular.2767

\section{POS1495-HPR THE EXPERIENCE OF A RHEUMATOLOGY UNIT DURING THE COVID19 LOCKDOWN: TELEMEDICINE ALLOWS A SAFE FOLLOW UP OF PATIENTS WITH RHEUMATIC DISEASES}

K. El Aoufy ${ }^{1,2}$, M. R. Melis ${ }^{1,2}$, S. Bellando Randone $e^{1,2}$, J. Blagojevic $^{1,2}$ F. Bartoli ${ }^{1,2}$, G. Fiori ${ }^{1,2}$, F. Nacci ${ }^{1,2}$, M. L. Conforti ${ }^{1,2}$, L. Cometi ${ }^{1,2}$, C. Bruni ${ }^{1,2}$, A. Moggi Pignone ${ }^{1,3}$, L. Rasero ${ }^{4}$, S. Guiducci ${ }^{1,2}$, M. Matucci-Cerinic ${ }^{1,2}$. ${ }^{1}$ University of Florence, Clinical and Experimental Medicine, Florence, Italy; ${ }^{2}$ Careggi University Hospital, Department of Geriatric Medicine, Division of Rheumatology, Firenze, Italy; ${ }^{3}$ Careggi University Hospital, of Emergency Medicine, Division of Internal Medicine, Firenze, Italy; ${ }^{4}$ University of Florence, Departement of Health Science, Florence, Italy

Background: In March this year, most of the routine activities were cancelled during the streaming of the pandemic in Italy. This prompted a pragmatic reorganization of the traditional care model of nursing and medicine, to quickly give an efficient clinical response. During the first phase of the pandemic, outpatient visits dropped by more than $60 \%$, forcefully shifting to telemedicine to assure continuity of care despite the lockdown.

Objectives: The aim of the present work was to describe the strategy adopted during and immediately after the lockdown to assure the follow up of patients and the maintenance of their treatment in an outpatient "virtual" telemedicine clinic dedicated to RDs. Methods: the patient flow to a rheumatology division during the lockdown was evaluated retrospectively from March to September 2020 in accordance with local restrictions, and three periods are described.

Results: $653 / 913$ (71.5\%), 542/542 (100\%) and 1.048/1.048 (100\%) infusion activities scheduled were performed at the centre for daily infusion and pre-infusion assessment, respectively during the $1^{\text {st }}, 2^{\text {nd }}$ and $3^{\text {rd }}$ period. In the outpatient clinic during the $1^{\text {st }}$ period, $96.96 \%$ of the cases was shifted to Telemedicine, which decreased to $52.45 \%$ in the $2^{\text {nd }}$ period; while in the $3^{\text {rd }}$ period, $97.6 \%$ of the performances were carried out at the clinic. Diagnostic procedures, such as ultrasound, capillaroscopy, and joint injection were generally postponed during the $1^{\text {st }}$ period, reduced drastically during the $2^{\text {nd }}$ and performed regularly during $3^{\text {rd }}$ period. Ulcer treatment and the Clinical Trial Unit never stopped their activity. The flow of the activity of the outpatient clinic and the day hospital is represented as monthly trends in graph 1 (See Graph 1)

Conclusion: Our data show the feasibility of Telemedicine in a lockdown condition. Shifting stable patients to Telemedicine has the potentiality to minimize the risk of contagion and allow continuity of care. In the future, the use of Telemedicine for specific clinical uses might assure patient assistance also in non-pandemic conditions.

REFERENCES:

[1] Rawaf S, Allen LN, Stigler FL et al. Lessons on the COVID-19 pandemic, for and by primary care professionals worldwide. Eur J Gen Pract. 2020 Dec;26(1):129-133. doi: 10.1080/13814788.2020.1820479. PMID: 32985278

[2] McDougall JA, Ferucci ED, Glover J, et al. Telerheumatology: A Systematic Review. Arthritis Care Res (Hoboken). 2017 Oct;69(10):1546-1557. doi: 10.1002/acr.23153. Epub 2017 Aug 22. PMID: 27863164; PMCID: PMC5436947.

[3] Romão VC, Cordeiro I, Macieira C, Oliveira-Ramos F, Romeu JC, Rosa CM, Saavedra MJ, Saraiva F, Vieira-Sousa E, Fonseca JE. Rheumatology practice amidst the COVID-19 pandemic: a pragmatic view. RMD Open. 2020 Jun;6(2):e001314. doi: 10.1136/rmdopen-2020-001314. PMID: 32584782 PMCID: PMC7425193.

Characters from table content including title and footnotes:

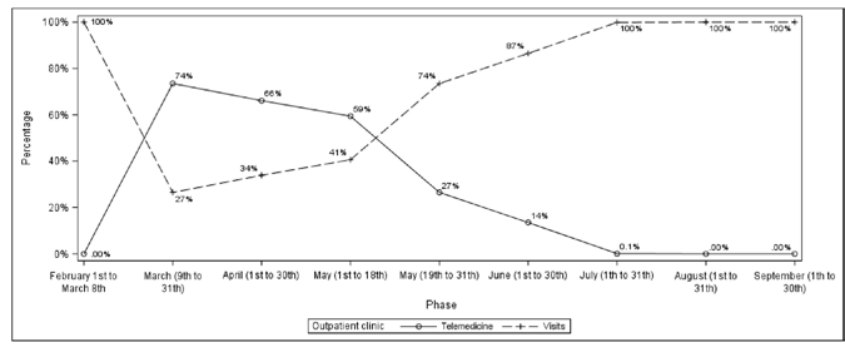

Graph 1. Monthly trend for telemedicine and visits during the SARS Cov2 emergency

Acknowledgements: The project (Telereuma) has been supported by an unrestricted grant of Biogen, BMS, and Novartis.

Disclosure of Interests: None declared

DOI: 10.1136/annrheumdis-2021-eular.3023

\section{POS1496-HPR IS NUTRITIONAL FOLLOW-UP IN PATIENTS LIVING WITH RHEUMATOID ARTHRITIS BETTER WITH TELECONSULTATION? - EXPERIENCE BEFORE AND AFTER PANDEMIC}

I. Mozo ${ }^{1}$, M. Marquez ${ }^{2}$, O. Valencia ${ }^{3}$. ${ }^{1}$ Fundación Santa Fé de Bogotá, Centro de Cuidado Clínico en Artritis Reumatoide, Bogotá, Colombia; ${ }^{2}$ Fundación Santa Fé de Bogotá, Nutrition, Bogotá, Colombia; ${ }^{3}$ Fundación Santa Fé de Bogotá, Research, Bogotá, Colombia

Background: Nutritional follow-up as part of the integral attention for patients living with rheumatoid arthritis (RA) has been limited due to the COVID-19 pandemic. It made necessary to implement a remote monitoring for the care of the patients and to evaluate the outcomes of the changes in the care model.

Objectives: To identify the effects of the telemonitoring intervention within the pandemic scenario and the outcomes of the traditional face-to-face nutrition consultation.

Methods: A retrospective analysis of health records and the administrative data base of the patient's follow-up, between 2019 and 2020, was developed at the arthritis specialized center of the Santa Fe de Bogotá Foundation in Bogotá, Colombia. The outcomes measured include the number of visits per year and the proportion of patients who attend their nutritional follow-up by telemonitoring in 2020 vs patients attending to face-to-face nutrition consultation. Differences in the Body Max Index (BMI) and the changes based on eating habits, defined by the quality of food consumption per day, were also measured.

Results: A total of 212 patients from 2020 and 179 from 2019 were analyzed; An increase of $61.5 \%$ in the number of consultations, using nutritional telemonitoring per year, was identified in $2020(n=412)$ compared to $2019(n=255)$. In patients followed from 2019 to $2020,13 \%$ (10/77) experienced an increase of more than 2 units of their BMI, while $22 \%$ (17/77) showed a decrease; in $2 \%$ of patients was not possible to evaluate their current weight; in the same way, 49\% (103/212) in 2020 showed a positive change in their feeding habits compared with a $12 \%(21 / 179)$ in 2019. 135 new patients were recruited for nutritional telemonitoring 2020 .

Conclusion: Nutritional telemonitoring to follow-up patients with RA has increased considerably in terms of consultations per year and changes in the feeding habits. However, more evaluation is required for this model. 